\title{
The measurement of operational risk capital costs with an advanced measurement approach through the loss distribution approach (A case study in one of the Indonesia's state-owned banks)
}

\author{
R. Hartini, S. Hartoyo \& H. Sasongko \\ School of Business, Bogor Agricultural University, Bogor, Indonesia
}

\begin{abstract}
The rapid growth of the banking business requires banks to adapt quickly and to be supported by reliable risk management. In contrast to the market and credit risks, an operational risk is the first risk type known by the banks, but the least understood compared to market and credit risks. Basel II (International Committee for setting up bank risk management) defines an operational risk as the arising risk from the failure of internal processes, people, systems, or external events. Basel II also sets the standard and internal calculation modelling that must be applied by the banks. This research discusses the method for a bank to measure the operational risk capital cost accurately with the Advanced Measurement Approach (AMA), that requires historical data (Loss Event Database) regarding operational loss events. This advanced approach uses mathematics and probabilistic calculation, that highly likely provides an accurate result. This research found that the Loss Distribution Approach has high accuracy for calculating operational risk on every event of the eight bank business lines. It is known that the largest fraud is derived from internal bank operation.
\end{abstract}

\section{INTRODUCTION}

Indonesia is one of the countries that has a banking industry with good performance. This can be seen from the level of ROA (Return on Assets) of 3.03\% (Bank Indonesia, 2011). In South East Asia, the average banking ROA level has reached 1.14\% (Firmanzah, 2011). This is a positive performance indicator of the banking industry in Indonesia, but there is still a lot of work to improve competitiveness regionally and internationally.

The ratio of the Indonesian banking BOPO level (Operational Cost of Operational Income) per December 2011 reached 85.42\% (Bank Indonesia, 2011a), or larger than the average BOPO in ASEAN (Assocoation of South East Asia Nations) by 40\%-60\% (Firmanzah, 2011). According to Firmanzah (2011), another indication discovered is the slow response of Bank Indonesia (BI) to decrease its benchmark interest rate, which points to $6 \%$. This rate is expected to improve the competitiveness of national banks against other neighbouring countries, whose own benchmark interest rates are relatively lower, such as Malaysia $(3.25 \%)$, Thailand $(3.50 \%)$, the Philippines $(4.50 \%)$, or Korea $(3.25 \%)$. Therefore, in order to increase the national banking competitiveness, the government needs to make interventions in improving the banks' performance, as well as in improving the efficiency of their business operations.

The government needs to develop bank mechanisms for supervision with high concentration. This is important in order to control the banks' operational activities so that they become more efficient, leading towards high competitiveness and avoiding practices that potentially lead to moral hazard. The central bank will implement a policy that will evaluate the ownership of shares through the value of the level of health and governance implicated against the level of health or bank performance. 
Operational risks become the most dominant type of risk compared to other risks. Different from various other risk types, an operational risk is the earliest known type of risk in the banking world, but little understood compared to other risks. Operational risks also have unique characteristics, because they are not associated with the expectations of the rate of return, but they occur naturally and appear as a result of business activities. Basel II (International Committee for setting up bank risk management) defines an operational risk as the risk that arises because of the failure of the internal process, man, system, or from external events. Basel II also sets up the model of the calculation and internal standards that must be applied by the banks.

The calculation of the operational risk burden, that might be the source of the potential losses to the bank, is yet to be measured accurately in the calculation of weighed assets according to the risk (ATMR). The bank must calculate ATMR to operational risks in the calculation of the minimum capital participation obligation (or Minimum Capital Requirement with various approaches:

1. Basic Indicator Approach;

2. Standardised Approach; and/or

3. AMAs (Advanced Measurement Approaches).

One of the internal approaches that is used and will be the focus of discussion in this research is the AMA, that is believed to have a high level of accuracy because it uses the mathematical and probabilistic approach. The advanced method requires historical data (Loss Event Database) on operational loss events. With the database, the bank can make an operational risk quantification model so that the projection of the capital charge can describe the estimated losses.

The understanding of the operational risks concept, along with the mathematical and probabilistic approach, becomes very important to be understood by practitioners in the business environment, especially for bankers and academics. The problem that arises is how the bank can measure operational risks and then implement mitigation (Operational Value at Risk/OpVar). This is the main focus in this research that was conducted in one of the Indonesian state-owned banks.

This research was implemented in one of Indonesia's state-owned banks, by considering its status as one of the largest banks in Indonesia, that will inevitably have systemic impacts should a crisis happen. This Indonesian state-owned bank is also considered as a representative bank as a reference regarding the number of assets managed owned by the customer and also the number of branch office, a cash office, and other business units reaching out to the remote rural areas.

\section{LITERATURE REVIEW}

\subsection{Risk definition}

Risk is associated with uncertainty or irregularities. The general understanding of a risk is also stated by Lee et al. (2001), explaining that risk can be defined as the potential for events or trends in progress that cause losses in the future or cause future income fluctuations. Hardanto (2006) defines risk as the likelihood of a bad result and the greatness of the opportunity that can be estimated.

The risk in the bank's context can be interpreted as a potential event that can be expected but which cannot be expected to have a negative impact on earnings and capital expenditure of the bank (Yulianti, 2009).

\subsection{Operational risks}

Operational risk is defined as the risk of direct or indirect losses resulting from the internal process and system that are inadequate or have failed, but can also be influenced by the external 
process (Esch et al., 2005). Buchelt and Unteregger (2004) define operational risks as one unity of risks of very diverse and interconnected risks with a different origin.

Djohanputro (2008) defines operational risks as a potential deviation from the results expected due to system malfunctioning, human resources, technology, or other factors. Fahmi (2010) states that the operational risk is the risk that generally originates from internal company issues, and in this case the risk of this happening is caused by a weak management control system that is implemented by the company's internal party. Operational risks according to Crouhy et al. (2001) are the operational risks as the external event risks or weaknesses in the internal control system to the detriment of the company.

\subsection{Operational risk capital burden}

According to Article 31 of the Bank Indonesia Regulation No. 10/15/PBI/2008 24 September 2008 regarding the obligation of providing general Bank Minimum Capital (or Minimum capital requirement), it states that the bank must calculate ATMR operational risks in the calculation or Minimum capital requirement using the following approaches:

1. Basic Indicator Approach (BIA)

2. Standardised Approach (SA)

3. Advanced Measurement Approach (AMA)

However, in the implementation of the initial phase, the calculation of ATMR required is done by using the basic indicator approach (PID), where ATMR is determined by the following formula:

$$
\operatorname{ATMR}=12.5 \times \text { Operational Risk Capital Burden }
$$

where

$$
K_{P I D}=\frac{\left[\sum\left(G I_{1 \ldots n} \times \alpha\right)\right]}{n}
$$

$\mathrm{K}_{\mathrm{PID}}$ : operational risk capital burden using the basic indicator approach (PID)

GI: annual positive gross income in the last three years

$\mathrm{n}$ : the number of years of positive gross income

$\alpha: 15 \%$

Some of the things that need to be noted are:

- Gross revenue is net interest income plus non-operational income of certain other interests, calculated by a cumulative net from the early period of January to the end of December each year.

- Calculation of gross income uses data that is delivered through the monthly bank report (LBU). In this case, the system changes LBU, and the bank uses the gross income according to the old LBU of the corresponding year.

- When the bank owns a sharia business unit, the gross income calculation from the sharia business unit is then converted in accordance with the characteristics of the bank business and sharia principles.

- The bank should make corrections if, based on the financial reports that have been audited by a Public Accountant, there are corrections regarding the amount of gross revenues.

- When calculating the average gross income for three years, and there are one or two years where the bank's gross income is negative or zero, the calculation of the average annual gross income of the bank should reveal the value of gross revenues from the negative quantifiers, and both should be operable when calculating the average gross income.

- When in a span of three years, and the bank's gross income is negative or zero, then the average gross income of the bank must be added to the operational risk capital burden using the latest annual positive gross revenue. 


\subsection{The model of the loss distribution approach}

The methods are most often used in the AMA and the Loss Distribution Approach (LDA). Using LDA, the bank can measure the frequency distribution and how great the loss of operational risks for each point risk (business line/event type) is within a period of one year (Chernobai et al., 2007).

\subsection{Value at risk}

The bank uses customer costs for risks, so that (hopefully) average losses in one market segment are compensated under Pakistani with other benefits. Other risks, especially the risks of the market and increased credit risks, are protected value (insured) through the market derivatives. Unexpected losses are not diversified or protected value (hedged), which is covered by the capital equity bank and how much bank capital is necessary to cover it. The risk is determined by what is called as Value at Risk (VaR).

Formally, VaR measures the lack of q-quintile as a result of the distribution of loss (losses distribution) that exceeds the expected loss (loss), EL in the time period, T discounted on the level of $r$ risk-free for time $t=0$ :

$$
\text { VaRq, T }=(\mathrm{QqL}(\mathrm{T})]-\mathrm{EL}) \mathrm{e}-\mathrm{rT} \text {, }
$$

where $\mathrm{q}$ - quintile is the case of worst loss (loss), $\mathrm{Qq}[\mathrm{L}(\mathrm{T})]$ defined on the level of trust $\mathrm{q}$ through

$$
\operatorname{Prob}(\mathrm{L}(\mathrm{T})>\mathrm{Qq}[\mathrm{L}(\mathrm{T})))=1-\mathrm{q}
$$

\subsection{The process of back testing}

According to Cruz (2002), the operational back testing is done by comparing VaR prediction based on historical data with the actual loss occurring. The model is acceptable when the number of deviations from the value of VaR with the actual loss does not exceed the requirements. The procedure for testing the validity of the model with back testing is to compare the value of the VaR operational risks with the realisation of operational losses in a certain period (Muslich, 2007).

\section{RESEARCH METHOD}

\subsection{Data and variables used}

The data used in this research is secondary data. The data used comes from the incident Management in Operational Risk Assessor Application (OPRA) and is combined with data collected from a variety of sources, including: the data loss that is managed by the division of the central operation of the data to the Internal Audit findings (AIN) which has not been put into OPRA applications, and other data which has definitely not been put into the incident management application. The data used in this research is loss frequency data and severity data, which is the monthly data from January 2008 to December 2012.

The variables used in this research are based on the assessment of the risk profile, consisting of the assessment of Inherent Risk (the risk inherent in the activity of the bank) and the assessment of the Risk Control System (the control of risk inherent) to eight business lines, namely corporate finance, trading and sales, retail banking, commercial banking, payment and settlement, agency services, asset management and retail brokerage, with seven categories of Genesis, namely internal fraud, external fraud, employment practices and for student placements safety, clients products and business practices, damage to physical assets, business disruption and system failures and execution delivery, and process management. 


\subsection{Data analysis}

\subsubsection{Descriptive analysis}

Descriptive statistics provides an explanation about the collection of quantitative size as risk indicators to describe data. Some numbers in the descriptive statistics give an overview of the characteristics of the data in which used in this paper.

\subsection{Testing the distribution of the frequency and severity}

The intended test is to prove the hypothesis as to whether the spread of the frequency of some specific distribution opportunities already meets the criteria of an opportunity spread. The distribution test uses the Chi-Square test and the Anderson Darling test.

\subsection{LDA analysis}

The test was intended to prove whether the hypothesis regarding the spread of the frequency of some specific distribution opportunities meets the criteria of a spread. Testing used the Chi-Square test and Anderson Darling test.

The LDA model used for the calculation of OpVar is a model that combines the frequency distribution and the distribution of the severity of the sample data loss. Genesis frequency distribution data is operational as the distribution of discrete graphics, while data operational loss severity distribution is a continuous distribution. In this LDA approach, total loss is the number of operations $(\mathrm{S})$ from variable random $(\mathrm{N})$ on individual operational loss $(\mathrm{X} 1$, $\mathrm{X} 2, \ldots, \mathrm{XN})$ so that the number of total operational losses can be stated as follows:

$$
\mathrm{S}=\mathrm{X}_{1}, \mathrm{X}_{2}<\ldots ., \mathrm{X}_{\mathrm{N}} \text { where } \mathrm{N}=0,1,2, \ldots \ldots
$$

The distribution of the total loss is then used to project the potential operational loss. One of the methods used for the conjunction is the Monte Carlo simulation. (Figure 1).

\subsection{The calculation of OpVar with Monte Carlo simulation}

The calculation of the OpVar estimation can be conducted with the help of a Monte Carlo simulation. The Monte Carlo simulation is the best way to produce a loss distribution or the distribution of losses. The Monte Carlo simulation is done through the process of combining the distribution of the frequency of a loss of data with the distribution of the severity of the lost data. This simulation is intended to produce a probability distribution of some possible results of experiments using random number data. The number of data points determines whether the number is big enough to ensure that the quality of the results does not provide

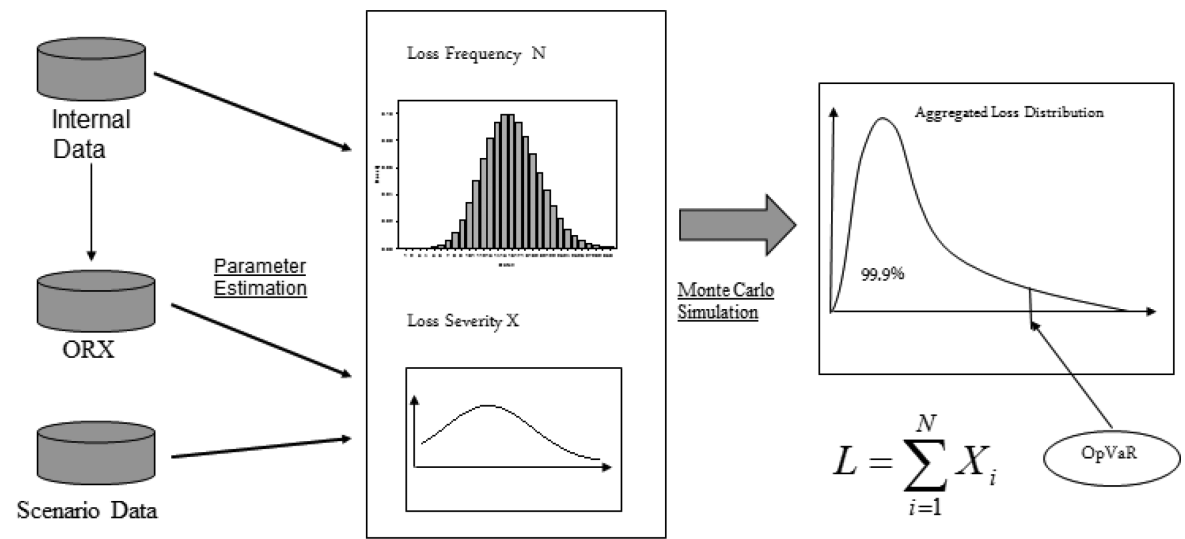

Figure 1. Aggregating severity and frequency models. 
a large error deviation. Therefore, the more the number of data simulation points $(>10,000)$, the more accurate the results and the more stable the data (Cruz, 2002).

\subsection{The process of back testing}

Cruz (2002) explains that operational back testing is conducted by comparing the prediction of VaR based on historical data with the actual loss occurring. The model can be accepted when the number of deviations from the value of VaR with the actual loss does not exceed the limit.

Testing the validity of the model of the operational risks utilises the testing hypothesis with the aim to see whether or not the model can be accepted.

$\mathrm{H} 0$ : correct model in the projected potential operational loss

$\mathrm{H} 1$ : the incorrect model in the projected potential operational loss

Kupiec uses the formulation of LR to test the validity of the model as follows:

$$
L R=-2 \ln \left[(1-p)^{T-N} p^{N}\right]+2 \ln \left[\left(1-\frac{N}{T}\right)^{T-N}\left(\frac{N}{T}\right)^{N}\right]
$$

where

T: number of samples of observation

$\mathrm{N}$ : the number of losses that exceeds the value of $\mathrm{VaR}$ (failure rate)

p: VaR confidence level

Then the value of the LR is compared with the Chi-Square critical value with 1 degree of freedom. If LR $>3.84$ then $\mathrm{H} 0$ is rejected, which means that the model is not correct/ not valid. Likewise, if the result of the validation model revealed is true/valid, then this will strengthen the policy of using the model. However, if the model stated is not true/not valid then the model used needs to be reviewed or replaced with another measurement model.

\section{RESULTS AND DISCUSSION}

To perform the modelling and measurement of potential operational risk losses, the distribution characteristics of operational risk losses must be known in advance. The distribution of operational risk loss data can be grouped into the distribution of data frequency and loss severity distribution of data losses. The data in Table 1 can be used for the process of the modelling and measurement of potential operational risk losses.

Table 1. Based on the Genesis data loss frequency and severity data.

\begin{tabular}{clllllll}
\hline & Genesis category & & & & \\
\cline { 2 - 7 } Business Line & $\begin{array}{l}\text { Internal } \\
\text { fraud }\end{array}$ & $\begin{array}{l}\text { External } \\
\text { fraud }\end{array}$ & $\begin{array}{l}\text { Employment } \\
\text { practices }\end{array}$ & $\begin{array}{l}\text { Product } \\
\text { clients }\end{array}$ & $\begin{array}{l}\text { Physical assets } \\
\text { damage }\end{array}$ & $\begin{array}{l}\text { Business } \\
\text { interruption }\end{array}$ & $\begin{array}{l}\text { Delivery } \\
\text { execution }\end{array}$ \\
\hline $\begin{array}{c}\text { Asset } \\
\text { management }\end{array}$ & Available & Available & Available & Available & Available & Unavailable & Available \\
$\begin{array}{c}\text { Retail banking } \\
\text { Retail } \\
\text { brokerage }\end{array}$ & Available & Available & Available & Available & Available & Available & Available \\
$\begin{array}{c}\text { Commercial } \\
\text { banking }\end{array}$ & Available & Unavailable & Unavailable & Unavailable & Unavailable & Unavailable & Unavailable \\
$\begin{array}{c}\text { Corporate } \\
\text { finance }\end{array}$ & Available & Unavailable & Unavailable & Unavailable & Unavailable & Unavailable & Unavailable \\
$\begin{array}{c}\text { Payment and } \\
\text { settlement }\end{array}$ & Available & Available & Unavailable & Available & Unavailable & Available & Unavailable \\
$\begin{array}{c}\text { Trading } \\
\text { and sales }\end{array}$ & Unavailable & Unavailable & Unavailable & Unavailable & Unavailable & Available & Available \\
\hline
\end{tabular}


To conduct the calculation of the large Operational VaR, the initial step that must be taken is to perform a test on the type of distribution used in this research. Testing the most suitable distribution type (Goodness of Fit Test) is based on the existing data. Distribution testing is done by using the software Easyfit and function of the Excel spreadsheet. If the operational loss distribution type testing is conducted in a timely manner and is true, then a model will be obtained to calculate the potential losses that will arise.

Incident management data was downloaded from the application of the OPRA on 26 June 2012. Furthermore, data collection from the AIN 2011 and data losses are managed by the division of the Operational Centre (STO). After verification and cleansing, experts were invited as speakers, and the data obtained is regarded as being clean data (believed to be good data), with descriptive statistics as shown in Table 2.

The spread of the data frequency and severity data for each business line per Genesis is determined based on the review of the spread and the form of the spread of the graph. Based on the review of Anderson Darling, it can be deduced that $\mathrm{H} 0$ can be rejected or accepted, where $\mathrm{H} 0$ is the data spread with certain spread (Table 3).

\subsection{The results of the calculation of the OpVar $99.9 \%$ and back testing}

After conducting the process sounding form of the spread of the data frequency and severity, futhermore we also test the spread of the data frequency and severity, the data combined is then implemented to determine the OpVar value with $99.9 \%$ degrees of trust of each business line per Genesis completed. After calculating the value of OpVar, back testing must be done to show that the alleged model is valid. The results of the calculation can be explained in Table 4.

Monte Carlo simulation results show that the value of OpVar is $99.9 \%$, produced from business line asset management with the internal event category fraud of 499,977,111,001,062. This means that the bank must provide capital to cover the risk of internal fraud of Rp499,977,111,001,062 (million) with the possibility of the worst incidents 0.1 out of 100 .

For the category of external fraud, the OpVar value that is produced with a reliability degree of $99.9 \%$ is $523,843,356,045,642$. This means that the bank must provide capital to cover the risk of external fraud amounting to Rp523,843,356,045,642 (million) with the possibility of the worst incidents 0.1 from 100 .

Table 2. Grouping of the incident operational risks and operational credit field 20072011 based on data sources.

\begin{tabular}{lcc}
\hline Data resource & The number of incidents & Total loss (Rp.) \\
\hline Fraud Audit TW1-2011 & 5 & 15.661 .006 .090 \\
Fraud Audit TW2-2011 & 9 & 9.699 .773 .871 \\
Fraud Audit TW3-2011 & 5 & 935.422 .379 \\
Fraud Audit TW4-2011 & 3 & 4.093089 .054 \\
OPRA-MI & 1059 & 3.725 .860 .395 .758 \\
Special Audit TW1-2011 & 12 & 79.340 .015 .125 \\
Special Audit TW2-2011 & 2 & 9.137 .051 .709 \\
Special Audit TW3-2011 & 4 & 17.563 .304 .145 \\
Special Audit TW4-2011 & 6 & 14.183 .821 .778 \\
STO & 22 & 6.854 .550 .000 \\
STO-Illegal Card & 23 & 1.138 .860 .851 \\
STO-Account Book Counterfeiting & 9 & 5.385 .100 .000 \\
Evidence AIN Major-TW1-2011 & 37 & 65.033 .608 .700 \\
Evidence AIN Major-TW2-2011 & 58 & 1.015 .796 .911 .986 \\
Evidence AIN Major-TW3-2011 & 68 & 164.605 .682 .063 \\
Evidence AIN Major-TW4-2011 & 88 & 459.473 .565 .205 \\
Total & 1410 & 5.594 .762 .158 .713 \\
\hline
\end{tabular}


Table 3. The distribution of the spread of frequency data opportunities and operational loss severity.

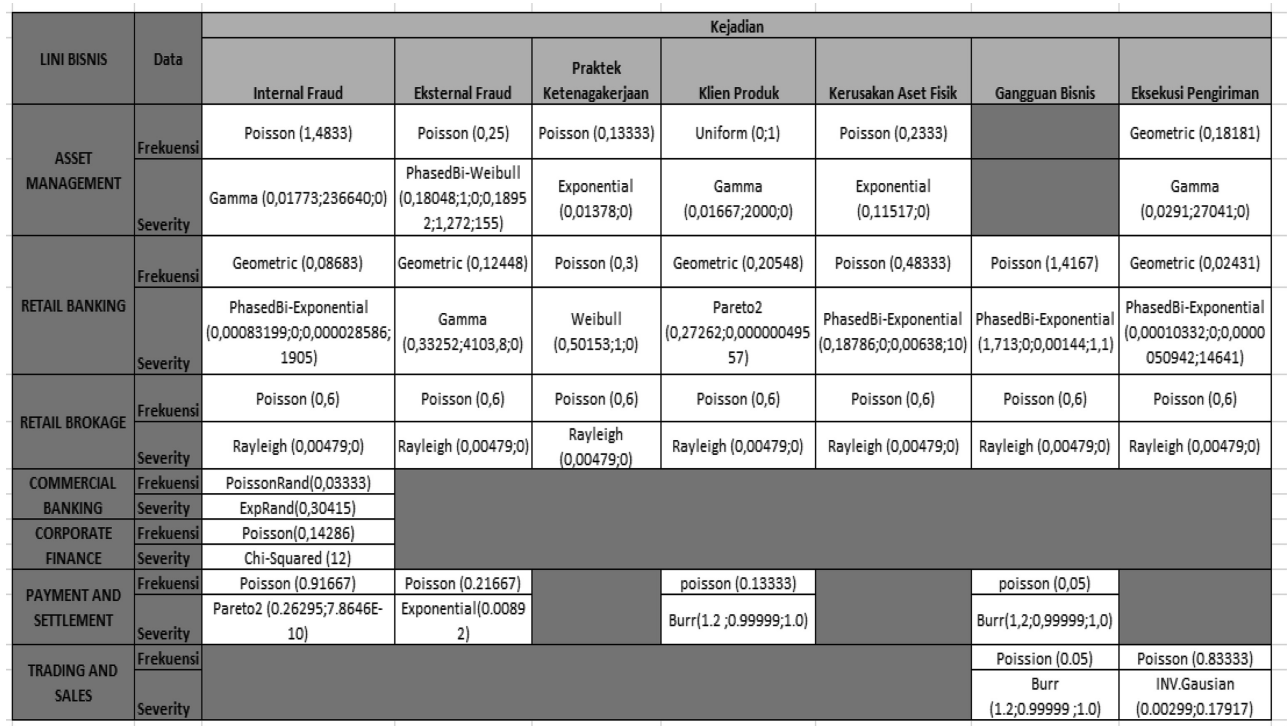

For the category of employment practices, the OpVar value that is produced with a reliability degree of $99.9 \%$ is $44,524,489,999,575$. This means that the bank must provide capital to cover the risk of employment practices amounting to Rp44,524,489,999,575 (million) with the possibility of the worst incidents 0.1 from 100 .

For the category of the product client, the OpVar value that is produced with a reliability degree of $99.9 \%$ is $133,018,844$. This means that the bank must provide capital to cover the risk of a Rp133,018,844 (millions) product client with the possibility of the worst incidents 0.1 from 100 .

For the category of physical assets of the damage, the OpVar value that is produced with a reliability degree of $99.9 \%$ is 483,332 , meaning that the bank must provide capital to cover the risk of damage to the physical assets of Rp483,332 (million) with the possibility of the worst incidents 0.1 from 100 .

For the category of delivery execution, the OpVar value that is produced with a reliability degree of $99.9 \%$ is $1,084,685,483$, meaning that the bank must provide capital to cover the risk of damage to the physical assets of $\mathrm{Rp} 1,084,685,483$ (million) with the possibility of the worst incidents 0.1 from 100 .

\subsection{The process of back testing}

Basically back testing is done by comparing the results of the estimation of the maximum loss (OpVar) with a certain confidence level with the actual operational losses. Based on Table 4, all earnings obtained of OpVar have LR value smaller than chi-sq cv, meaning that $\mathrm{H} 0$ accepts the risk calculation model and it is considered fit or valid.

\subsection{Fraud prevention efforts}

Based on the value of the OpVar table with a reliability level at $99.9 \%$, for each category of Genesis losses - internal fraud, external cheating (external fraud), employment practices and the safety of the workplace, clients, products and business practices - the destruction of the physical assets, business interruption and the failure of the system and the execution and delivery, and the management of the process from the $\mathrm{ABC}$ seven business line such as asset management, retail banking, retail brokerage, commercial banking, corporate finance, payment and 


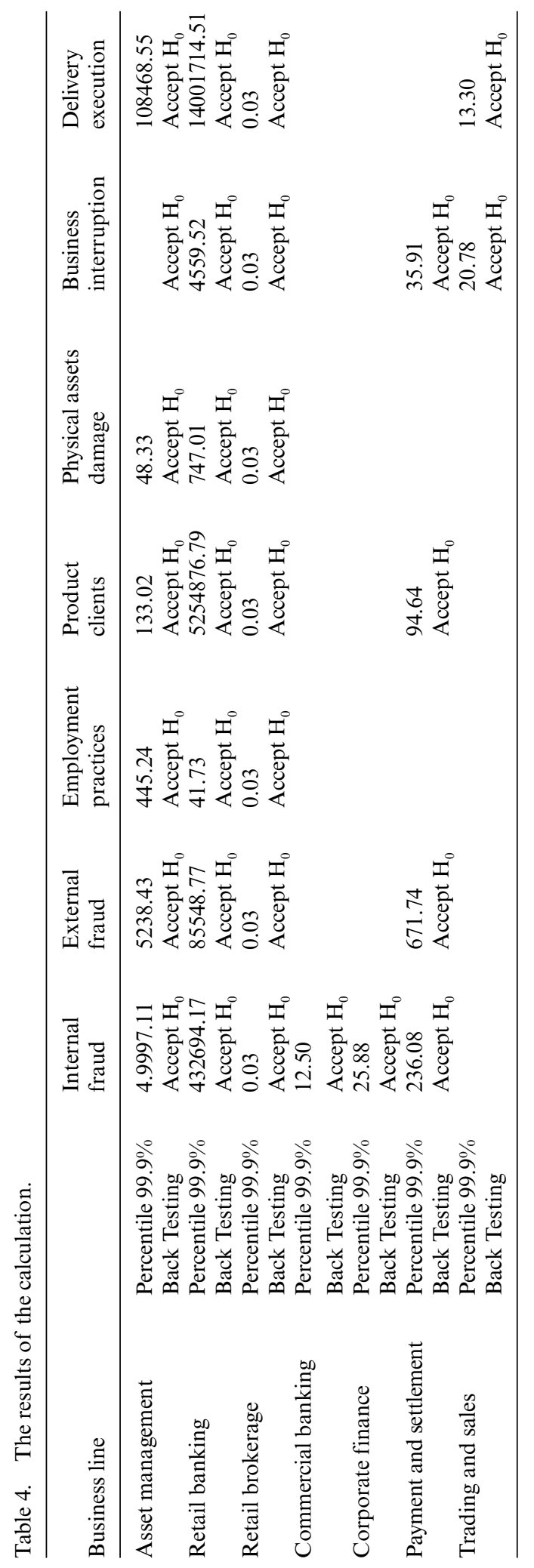


settlement and trading and sales, internal fraud contributes most of the loss to the company. This is shown by the value of the largest OpVar located in the category of internal deviation.

In the operational practices of banking, various types of internal fraud often occur, such as embezzlement, procedures, and violations of the law or the existence of a policy issued by each leader at each structural level.

Fraud prevention in the practice of banking operations is brought to the attention of the local and international world. Various prevention efforts, from the restricting supervision system to the prevention through corporate culture, are implemented and include ABC.

$\mathrm{ABC}$ has a number of fraud prevention programmes that have been inaugurated in a culture of anti-fraud. All employees to the board of directors and $\mathrm{ABC}$ commissioners must be involved in the drafting and socialisation statement of anti-fraud. ABC also has published a book titled Top 50 Risk Issues as a reference to employees to make them aware of the critical points which are prone to corruption. Regularly ABC sent letters of increased control to the entire work unit. Any risk management forum will be held to analyse the current problems faced by the company. Employees are also required to fill out an annual statement (annual disclosure) at the end of each year related to the clash of interests in the transaction activities implemented.

\subsection{Managerial implications}

The status of $\mathrm{ABC}$ as a public company (Tbk) should allow zero tolerance against fraud that will have a direct impact on the financial losses. In view of this research, the researchers see that $\mathrm{ABC}$ needs to evaluate the effectiveness of the anti-fraud system which is currently being implemented.

Basically, risk management banks have international standards that are under the supervision of an institution called the Bank for International Settlement (BIS). BIS oversees the banking risk management committee Basel II. This committee makes the standardisation of risk handling for all the banks in the world.

The board of directors must be aware of the major aspect of the operational risks of the bank that should be managed and approve and periodically review the framework of operational risk management bank. The framework must be trustworthy and refer to the definition of the correct operational risk.

An internal audit must be conducted on a regular basis against the framework of operational risk management and should be conducted by an independent and competent internal team. The board of directors plays an important role in this case to ensure that the audit process is run independently.

\section{CONCLUSION}

Based on the above, a conclusion can be made that the methods of the LDA has a high accuracy to calculate the number of OpVar on every event for eight business lines and seven categories of Genesis.

Based on calculations results from OpVar with reliability level of $99 \%$ also show that the largest deviations are in the field of Internal Fraud. In that case, the board of directors and also the entire line of senior management have the responsibility to establish a corporate culture that is anti-fraudulent and prioritises the systemisation of effective operational risk management, which is subject to a healthy operational control.

\section{SUGGESTIONS}

According to the discussion and conclusion, the authors suggest that bank ABC should implement an advanced methods in measuring the operational risks, not only using the LDA, 
but can also make use of other advanced methods in order to see the comparison between the results with the level of increase.

The importance of data management and data input validity will be utilised to calculate the value of the risks, and thus produce accurate risk value sounding so that it can find the correct policy in accordance with the principles of data: garbage in is equal to garbage out.

\section{REFERENCES}

Bank Indonesia. (2003). Peraturan Bank Indonesia Nomor 5/8/PBI/2003 tentang Penerapan Manajemen Risiko Bagi Bank Umum. BI. Accessed on May 19, 2013, http://www.bi.go.id/biweb/utama/ peraturan/pbi-5-8-2003-eng.pdf

Buchelt, R. \& Unteregger, S. (2004). Cultural Risk and Risk Culture: Operational Risk After Basel II. Financial Stability Report 6. Accessed on June 29, 2013, http://www.oenb.at/en/img/fsr_06_cultural_risk_tcm16-9495.pdf

Chernobai, A.S., Rachev, S.T. \& Fabozzi, F.J. (2007). Operational risk: A guide to Basel II capital requirements, models, and analysis. New Jersey: John Willey \& Sons.

Crouhy, M., Galai, D. \& Mark, R. (2001). Risk management. New York: McGraw-Hill.

Cruz, M.G. (2002). Modeling, measuring and hedging operational risk. West Sussex: John Wiley \& Sons.

Djohanputro, B. (2008). Manajemen risiko korporasi terintegrasi. Jakarta: PPM.

Djojosoedarso, S. (2003). Prinsip-Prinsip manajemen risiko asuransi. Jakarta: Salemba Empat.

Esch, L., Kieffer, R. \& Lopez, T. (2005). Asset and risk management: Risk oriented finance. West Sussex: John Wiley \& Sons.

Fahmi, I. (2010). Manajemen risiko, teori, kasus dan solusi. Bandung: Alfabeta.

Firmanzah. (2011). Daya saing perbankan. Neraca.

Hardanto, S.S. (2006). Manajemen risiko bagi bank umum: Kisi-Kisi ujian sertifikasi manajemen risiko perbankan tingkat i. Jakarta: Elex Media Komputindo.

Lee, F.M., Marshall, A., Szto, Y.K. \& Tang, J. (2001). The practice of financial risk management: An international comparison. Thunderbird International Business Review, 43(3), 365-375.

Muslich, M. (2007). Manajemen risiko operasional: Teori dan praktik. Jakarta: Bumi Aksara.

Yulianti, R.T. (2009). Manajemen risiko perbankan syariah. In Jurnal Ekonomi Islam, 3, 151-165. 